\title{
Urban Unemployment in Nepal with Reference to Engineering Graduates of Kathmandu
}

\author{
Punneshori Shakya \\ Economics Instruction Committee, Pulchowk Campus, Institute of Engineering, Tribhuvan University, Nepal \\ Corresponding email: punne_ioe@hotmail.com
}

\begin{abstract}
The greater percentage of the graduates living in and outside Nepal is employed but they are not satisfied with the employment due to less salary scale. The respondents were from 23-50 age groups who graduated in between 1989 to 2000. Eighty one percentages of the respondents are currently living in Kathmandu valley, fourteen percentages are outside the valley in Nepal and five percentages are currently outside Nepal. The origin of the graduates is almost equally from both Kathmandu valley and outside the valley. The graduates are from various engineering backgrounds such as mainly from civil engineering followed by electrical and electronics engineering, architecture engineering, computer engineering and mechanical engineering. The survey shows that seventy seven percentages are not satisfied with their salary as the income range is not sufficient. This underemployment has led to economic, social and psychological problems. The survey reveals that political instability in the country is the main cause for current unemployment or underemployment followed by lack of opportunities and corruption. The respondents expressed that with political stability in the country organizational development can be enhanced which plays significant role in the employment process. Better education with proper educational policies also leads to skilled graduates that can meet the demand of the global market. According to the survey government is mainly responsible for the unemployment problem in the country and government should play an important role in formulating better economic policies, political stability with secured opportunities for investors and organizational development through international links for better employment opportunities establishing new job areas.
\end{abstract}

\section{Introduction}

\subsection{Nepal's Statistics}

The population census 2001 showed that around $86 \%$ of the country's population live in rural areas which are characterized by wide spread poverty, social backwardness and underdevelopment. Disparities between haves and haves not have been widening over the years. According to the living standards survey (1996), 44 percent of the population in the rural areas lives under the line of poverty; it is 23 percent for those in the urban areas. Excluding Kathmandu valley, 34 percent of the people in other urban areas live in poverty. The Nepalese social structure is divided into a hierarchy based on caste and gender and is diverse. Apart from this, lack of social awareness, education and health services and cultural and gender based discriminations remain as obstacles to social and cultural empowerment. Similarly, the disparity in income has grown as a result of which the gap between the rich and poor has been widening. The unequal distribution of resources remains a major impediment to sustainable development. 
This inequality has played a negative role in the context of poverty alleviation and development. Slow development of economic infrastructures and unbalanced social and economic development have created high unemployment.

Bad governance and irresponsibility are other challenges to development. Foreign aid has not been adequately mobilized in Nepal because of these negative aspects. Nepal's main development objective is poverty alleviation. But the country has been facing great challenges in the implementation of poverty alleviation programs because of insufficient resources, decreasing development funds, high costs because of weak implementation capacity, weak management, corruption, incompetence and increasing security expenditure. The lack of agreement between the political parties and the ongoing conflict has added additional problems to Nepal's economic sector. In Nepal's development forum 2002, the government has stated that it plans to reduce poverty from 38 percent to 20 percent during the 10th plan period. But, the goal has been amended since and the government plans to bring poverty level down to 30 percent at the end of the 10thPlan.

\subsection{Global and National Scenario on Engineering Education}

The technological revolution has confined the world to a global village. However, technological gap is increasing day by day. Developed countries have set the priorities on the engineering education (WB, 2000). The scenario of developing countries such as Nepal is poor. State to the larger extent is placing less priority to the engineering education. The system, monitoring and quality control is fruitless. Substantial numbers of high skill manpower are draining out. The unemployed rate is $5.1 \%$ of the economically active population (of ten years and above). The under employment problem is even more severe in Nepal and is estimated to be $38.4 \%$ in the rural areas and $15.7 \%$ in the Urban areas (Shrestha, 1997).

The engineering education and the technology development is the center point of development policy. There must be engineering education compatible with the ground reality of the country. Despite many attempt of formulating different engineering educational policies, the planning process in Nepal is not mitigating the change in the society. In other words, the country is not grasping the essential technology, eventually the change, thus reflecting into educational policies. Engineering education has to be considered linking with the development of the country. The role of government and all component of society should be the development of the country and the prosperity of the people. To be more precise, engineering education is the backbone of development.

\subsection{Brief History on Engineering Education in Nepal}

With the implementation of the national education system plan in 1972, Nepal Engineering Institute at Pulchowk and Technical Training Institute at Thapathali were brought together to form the Institute of Engineering under the Tribhuvan University. The Institute of Engineering (IOE) is committed to producing trades' men, technicians and engineers who are capable of accelerating the pace of the country's development. While this will always be the main objective of IOE, it is also capable of offering a wide range of services in addition to running the regular courses for the benefit of the country. This capability is well reflected from the large number of technical staff of various disciplines in the employment of IOE and large number of well equipped laboratories and workshops that are at its disposal. In fact, the potential of IOE, staff and physical facilities cannot be matched with any other agency in the country. 
The national education committee was formed by the government in 1961A.D. This committee had put forward the recommendation to change technical School to Engineering college under the Tribhuvan University. The recommendation of this commission can be taken as a land mark in the process of developing engineering education. It has emphasized on the need of engineering manpower for the development of the country. The four areas of engineering education were identified namely Engineering, Agriculture and Animal Science, Forestry and Medicine. Regarding engineering education, the commission recommended that institute of engineering should be established as a centre for producing quality engineering manpower and promoting and developing technology as require in the national development process. It also talked about the planned system of engineering higher education. In addition to this, it has proposed the board of engineering and vocational training and education to conduct trade course and training. This commission has streamlined the engineering education to the national policy as the basis of development

\section{The Statement of the Problem}

There are large numbers of unemployed engineering graduates in the market. It is shame for a developing country to have unemployed engineers. The numbers of engineering graduates are still increasing in the years to come. Total annual student intake capacity to all the engineering colleges in Nepal is 4708 . There are 29 engineering colleges in the country (The Rising Nepal, 2008). The engineering graduates produced in the country during nineties were hardly 96 . This number will rise to 2625 in 2005 (CBS, 2003). The problems illustrated are low pay, existing social norms/values, ineffective implementation of laws and regulation, lack of political commitment and hopeless condition of the country for the delinquency observed in the engineering profession.

As the country is heading towards declining economic status due to various political instabilities the dilemma of urban unemployment is obvious in the country. Especially, the condition of Kathmandu, the capital is worsening far beyond due to shifting of people to the city from all over the country in search of safe and secure dwelling places and opportunities for work as most of the working stations have been destroyed by the political situation of the country.

\section{Results and Discussions}

A total of 100 questionnaires were collected in the survey from November 2008 to May 2009. The Engineering graduates were of 23-50 age groups who graduated in between 1989 to 2000 . $51 \%$ of the graduates who filled the questionnaire are originally from Kathmandu valley whereas $49 \%$ are from outside the valley. The graduates expressed that the main reason for moving into the capital is education and work. The survey indicates that $81 \%$ of the graduates who filled the questionnaire are currently living in Kathmandu valley whereas $14 \%$ are living out of the valley in Nepal and 5\% are living outside Nepal.

The questionnaire sample includes $46 \%$ of graduates from Bachelors in Civil engineering, $20 \%$ from Bachelors in Electrical and Electronics Engineering, 16\% from Architecture Engineering, $9 \%$ from Computer Engineering and only 2\% from Mechanical Engineering. In the sample of engineering graduates $42 \%$ of the graduates are not enrolled in Masters Degree at present. $14 \%$ are enrolled in Masters Degree in Water Resources Engineering, 12\% are engaged in Urban Planning and Structure Engineering, 5\% in Environmental Engineering and Power System Engineering and only 4\% in Electrical Engineering. 


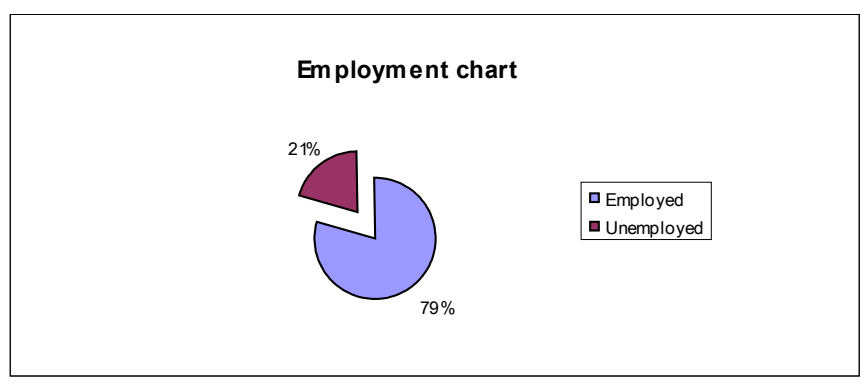

Figure 1: Employment Chart

The employment chart indicates that $79 \%$ of the engineering graduates are employed whereas $21 \%$ are unemployed. The employed graduates are enrolled in governmental sectors, teaching sectors, software companies, consultancies, construction and hydropower projects.

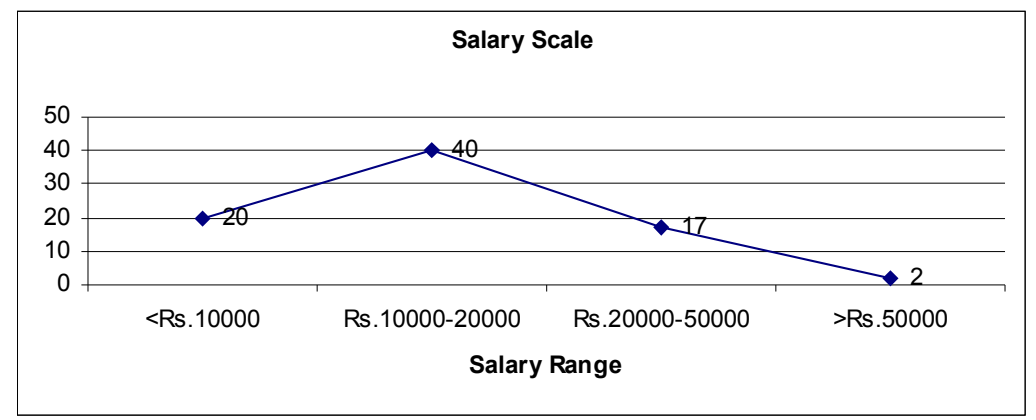

Figure 2: Salary Scale of the Graduates

It is observed that most of the employed graduates have the salary scale of Rs.10000-Rs.20000 whereas very less number of graduates have salary scale of greater than Rs.50000.

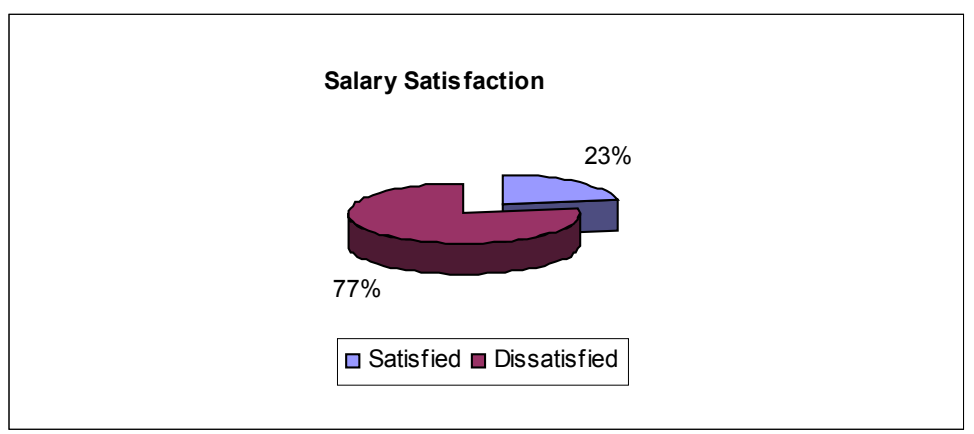

Figure 3: Salary Satisfaction 
$77 \%$ of the respondents are not satisfied with their salary range whereas only $23 \%$ are satisfied. This survey reveals that current income range is not sufficient for the engineering graduates.

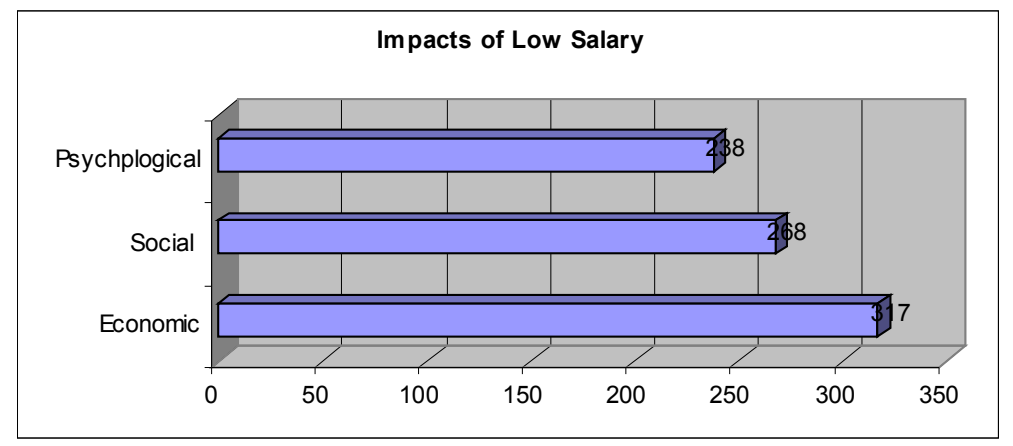

Figure 4: Impacts of Low Salary

The graduates indicate that the impacts of low salary is very high amongst which economic impact is the highest followed by social and psychological impacts.

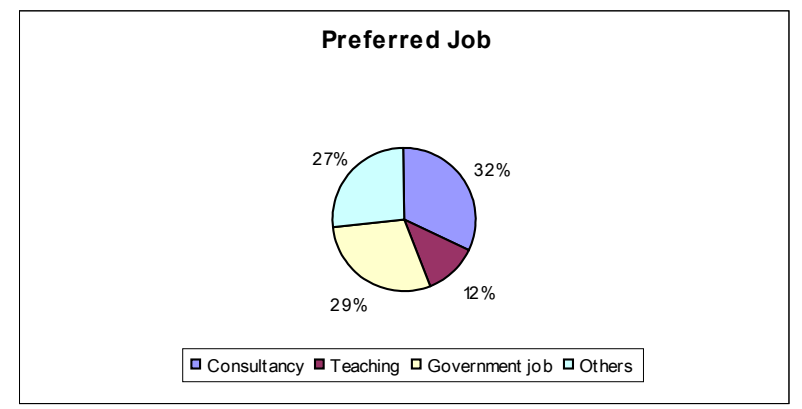

Figure 5: Job Preference of the Graduates

$32 \%$ of the graduates expressed that they prefer jobs in consultancies, $29 \%$ prefer jobs in governmental sectors and $12 \%$ in teaching sectors. Others preferences include own business, software companies, hydropower projects, developmental field such as NGOs and INGOs.

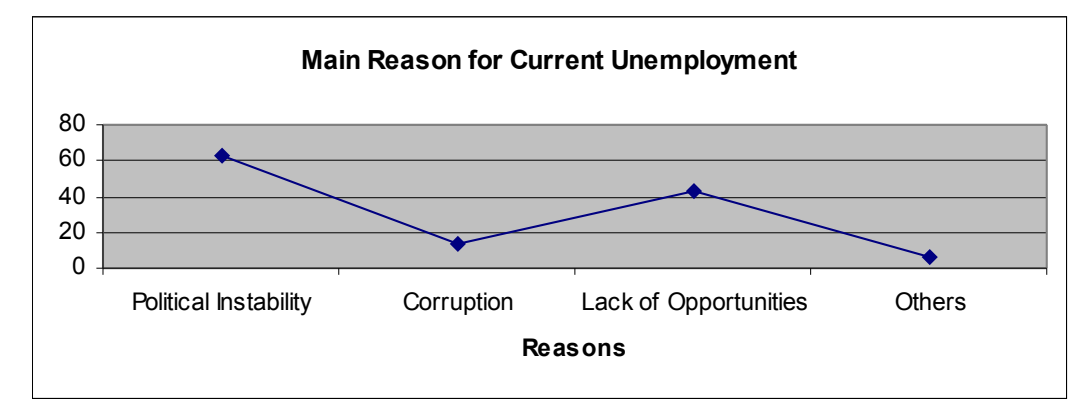

Figure 6: Reason for Current Unemployment 
From the survey it can be said that political instability is the main reason for current unemployment problem in the country. Also, lack of proper opportunities for skilled graduates in the country plays significant role in unemployment problem.

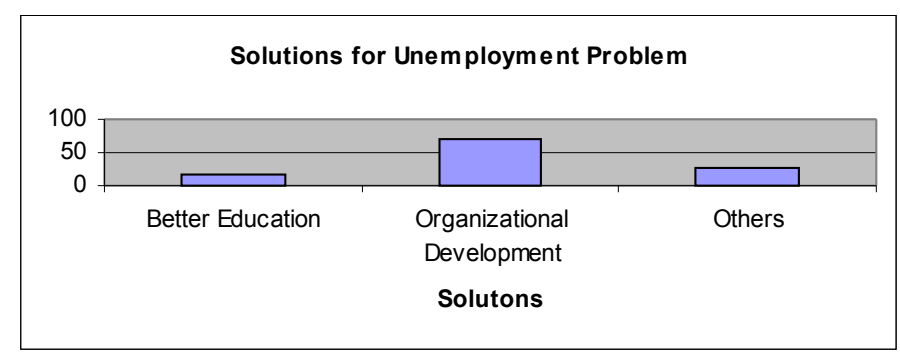

Figure 7: Solutions towards Unemployment Problem

Organizational development plays significant role in solving the unemployment problem in the country followed by better education. Also, the graduates reveal that opportunities for industrial development due to political stability and links to multinational companies will create employment opportunities in the country.

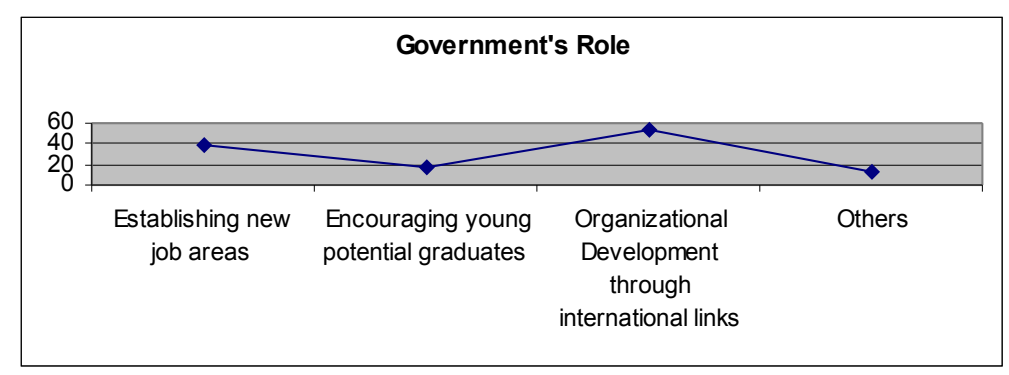

Figure 8: Government's Role in Employment Opportunities

The survey reveals that government has an important role in organizational development through international links in order to enhance the employment opportunities in the country. This will assist in establishing new job areas. It is also revealed that better economic policy, political stability in the country and secured opportunity for investors are the responsibilities of the government. 


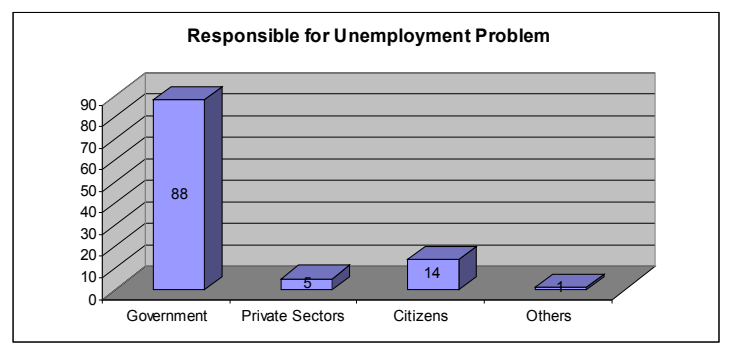

Figure 9: Sectors responsible for Unemployment Problem

$88 \%$ of the graduates have expressed that government is mainly responsible for the unemployment problem in the country whereas only $14 \%$ and $5 \%$ responsibility goes to citizens and private sectors respectively.

\section{Conclusion}

Nepal at present is under the vicious circle of poverty and economic stagnation. Slow development of physical and economic infrastructures, unbalanced social services and ineffective urban management system due to increasing urban population has created high unemployment. Bad governance, political instability, irresponsibility and improper mobilization of foreign aid are other challenges.

Consistency in engineering education policy is important as it is linked with the development of the country. Since few years back the conservative government began privatization in education but it is not effective. Lack of opportunities pushes many rural youth to seek a living in cities. Privatization in education has strengthened regional, social and economic inequality and exclusion by leaving out poor, marginalized and rural people. There has been some reaction in private sectors that the graduates of engineering are having difficulty is adapting with the working environment. The problems illustrated are low pay, existing social norms/values, ineffective implementation of laws and regulation and lack of political commitment. The majority of the engineering colleges within the capital valley are lacking the basic amenities to impart quality engineering education due to improper management, logistics support, human resources and infrastructures. Frequent evaluation and monitoring of academic institution is required to maintain quality education. An umbrella association should provide guardianship to all engineers and safeguard the rights and strengthen the professional capacity of the engineers. Engineers would have very big responsibility in the restructuring of new Nepal, lauding the role and contribution of engineers in the nation building.

The survey concludes that greater percentage of the graduates is employed. However, they are not satisfied with their jobs due to less salary scale. This under employment leads to high economic impact followed by social and psychological impacts. Most of the graduates come from the valley and those who come from outside the valley have moved into the capital for education and work opportunities which is getting harder to fulfil. From the survey it can be said that political instability is the main reason for current unemployment problem in the country. Also, lack of proper opportunities for skilled graduates in the country plays significant role in 
unemployment problem. Organizational development plays significant role in solving the unemployment problem in the country followed by better education. Also, the graduates reveal that opportunities for industrial development due to political stability and links to multinational companies will create employment opportunities in the country. The government has an important role in organizational development through international links in order to enhance the employment opportunities in the country establishing new job areas. It is also revealed that better economic policy, political stability in the country and secured opportunity for investors are the responsibilities of the government.

There is ever going belief in the Nepalese society that engineering sector opens wider avenues for opportunities for better jobs but often engineers are not satisfied with income from their jobs. Fresh engineers are time and again under employed or unemployed. These days, a qualified engineer seeks jobs in established organizations in the country or abroad for better opportunities and the country is loosing its human capital. Therefore, Nepal can be prosperous if opportunities for the people are improved and upgraded.

\section{Recommendations}

- Political stability should be prioritized in the country for stable condition that will lead to organizational development in the country for better employment opportunities and government should be mainly responsible for this development

- Nepal should mobilize support from the international community, involve young people in urban planning and strengthen urban governance, which implies both increased state responsibility and partnership with the civil society by responding effectively to the local needs. Multinational exposure is only good for technology transfer to Nepal

- Better education and skill development and appropriate environment in the country should be established that will itself create employment opportunities

- Increase entrepreneurship by soft loan for producing construction materials, licensing for design, estimate, supervision only by engineering graduates and regulate by minimum standard of payment to them, prohibit foreign employee in Nepal and discourage corruption

- Young graduates and their talents should be identified by the state and also should formulate such plans and policies to hold such graduates. When it is not done in a timely manner the country cannot utilize its graduates as all of them having skills are forced to go abroad and use their skills for survival. In such case graduates may earn and support their family but the country will always be deprived of the young enthusiastic minds and creation.

Engineering graduates of the country can play significant roles in the development of the country and enhance the economic situation by:

- Supporting the development process

- Properly utilizing the acquired knowledge and creativity in their respective fields in the country itself with firm determination and vision to establish new industries in the country which will contribute to the economic development as their knowledge, skill and technically sound brain is the backbone of the national physical development

- Becoming entrepreneurs and taking initiative to develop, create job opportunities themselves rather than seeking jobs elsewhere and letting national economy flow outside the nation. Self employment and getting jobs from abroad being a good centre for outsourcing 
- Planning appropriate utilization of available natural resources and presenting it to the decision maker taking into account the development of the country

- Engineers play key role in infrastructure development and if it done appropriately economic situation will be improved. Provision of employment can be ensured by physical infrastructure and social services by developing effective urban management system at the urban level.

- Uplift the economic situation by working sincerely with discipline and obey the rues and regulations of the nation and it should be prioritized by the government

- Using the sustainable and appropriate local technologies and controlling imported technologies

- $\quad$ Proper engineering approach in making national plans and applying sound knowledge of management on performing programs and projects considering national vision, mission and goal

- Providing technical support, decision making, planning, research mobilization and management of data and results for decision making

\section{REFERENCES}

[1] Ahuja, H.L. Advanced Economic Theory (Micro Economic Analysis). First Edition. Chand and company limited., Ram Nagar New Delhi

[2] Bajracharya, Prof. P. 1999. Introduction to Economics

[3] CBS, (2003), Statistical Year Book of Nepal, Central Bureau of Statistics, Kathmandu, Nepal

[4] Chopra, P.N. (1995). Macro Economics. First Edition. Kalyani Publishers

[5] Chopra, P.N. (2003). Macro Economics. 3rd Edition. Kalyani Publishers

[6] Employment Opportunities for Youth, January 2008, Rising Nepal

[7] Ghimire, P. Rising Nepal. (29 January 2006). Growth and poverty reduction Dilemma

[8] Jhingan, M.L. \& Shrestha, B.P. The Economics of Development and Planning

[9] Joshi, Dr J. (1987). Housing and Urban Development, National Planning Commission, Kathmandu.

[10] Journal of IOE, December 2006

[11] Lekhi, R.K. 1990. The Economics of Development and Planning. First Edition. Kalyani publishers

[12] Millan, Mac. Theory of Price

[13] National Planning Commission (2008)

[14] NGO Federation Nepal. International development assistance and civil society concerns in Nepal

[15] Pahari, B (2006), Quality of Engineering Education and Economic Growth in Nepal: Issues and Challenges, Journal of The Institute of Engineering, Volume 6 (1), Tribhuvan University, Institute of Engineering, Pulchowk, Kathmandu

[16] Pigou, A.C. \& Nepal, Dr G. The Economics of Welfare

[17] Shrestha, B. P. An Introduction to Economics

[18] Subrahmanyam, V.V. and Bawa, R.L. Urban Economic Development in India, Galgotia Publishing Company, New Delhi

[19] The Rising Nepal, 18 September, 2008

[20] Upadhyaya, B.N. (1982). How to live with engineering skills? IOE 
[21] WB, (2000), Higher Education in Developing Countries: Peril and Promise, A report developed by the Task Force on higher education and society formed by World Bank and UNESCO, 2000 